\title{
O trabalho docente no curso de formação da academia da Polícia Civil/SC: memórias das primeiras alunas $(1967-1977)^{1}$
}

\author{
Maria Aparecida Casagrande ${ }^{2}$ \\ Giani Rabelo ${ }^{3}$
}

\section{INTRODUÇÃO}

O trabalho docente é analisado neste texto através das memórias de oito alunas que frequentaram o curso de formação policial na Academia da Polícia Civil de Santa Catarina - ACADEPOL/SC, na primeira década de sua existência, ou seja: 1967 a 1977.

Na Polícia Civil, a presença feminina é recente e respondeu, principalmente, a uma pressão social que decorreu dos movimentos feministas das décadas de 1960, em âmbito internacional e dos anos de 1970, no Brasil. Esses movimentos incentivaram a inserção das mulheres no mercado de trabalho em diversas áreas, entre as quais as forças policiais.

A construção teórico-metodológica desta pesquisa circunscreve-se no campo da História da Educação, tendo três conceitos centrais: Gênero, Memória e Cultura Escolar. A História Oral foi a principal metodologia empregada para a coleta de dados, permitindo que as alunas se pronunciassem contando suas vivências e ressignificando suas lembranças com relação ao trabalho docente vivenciado à época. Sutis relatos sobre o trabalho docente fizeram parte desse cenário que revelou que algumas alunas entrevistadas já tinham experiências com o trabalho docente, deixando vestígios de que, na década estudada, as mulheres foram em busca de novas alternativas de trabalho, como a escolha pela polícia civil. Do mesmo modo, tais depoimentos revelaram que na época pesquisada, na ACADEPOL/SC, o trabalho docente era majoritariamente masculino; uma única professora é rememorada pelas entrevistadas, vez que a hegemonia masculina imperava e ainda impera nas instituições policiais. Ficou evidente

\footnotetext{
${ }^{1} \mathrm{O}$ texto apresenta um recorte da dissertação intitulada Mulheres Policiais: formação e atuação profissional das primeiras alunas da Academia da Polícia Civil de Santa Catarina (1967-1977), defendida no ano de 2013, no Programa de Pós-Graduação em Educação da Universidade do Extremo Sul Catarinense - UNESC. A referida pesquisa foi realizada com o apoio financeiro do Fundo de Apoio à Manutenção e ao Desenvolvimento da Educação Superior - FUMDES da Secretaria da Educação do Estado de Santa Catarina.

2 Graduada em Serviço Social. Especialista em Relações Humanas no Trabalho, Especialista em Segurança Pública, Especialista em Gênero e Diversidade. Mestra em Educação. Email: maparecida@ pc.sc.gov.br

${ }^{3}$ Doutora. Docente do Programa de Pós-Graduação em Educação (PPGE-UNESC) Email: gra@unesc.net
} 
que o conteúdo ensinado na perspectiva masculina denota, de forma profunda, uma cultura escolar com marcas do gênero masculino.

\section{O ESPAÇO EDUCACIONAL DA ACADEPOL/SC E PERCURSO METODOLÓGICO}

A ACADEPOL/SC ${ }^{4}$ foi criada por força de lei, no ano de 1964, à época denominada Escola de Polícia, mas somente em 1967 passou a funcionar com atividades de formação e capacitação de policiais. Cabe mencionar que a Escola de Polícia foi assim chamada até o ano de 1974, quando passou a se denominar Academia da Polícia Civil de Santa Catarina - ACADEPOL/SC.

É a ACADEPOL/SC o órgão responsável pelo curso de formação das carreiras ${ }^{5}$ de Delegado de Polícia, Psicólogo Policial, Escrivão e Agente de Polícia, bem como pela capacitação e aperfeiçoamento de todos/as os/as policiais civis do Estado de Santa Catarina.

A ACADEPOL/SC representa, no âmbito educacional, enquanto espaço de ensino e aprendizagem, uma parte do conjunto das instituições responsáveis pela produção, sistematização e transmissão de saberes e práticas, com uma cultura própria, carregada de historicidade.

A educação, em seu contexto geral, não acontece somente na escola. Conforme Brandão, existem difusos modelos. Para o autor, a "educação aparece sempre que surgem formas sociais de condução e controle da aventura de ensinar-e-aprender" (BRANDÃO, 2007, p. 26). Desse modo, entendemos que a educação é plural e concebida de modo interativo, assumindo uma dimensão social; além disso, quando tratada no âmbito da segurança, assume múltiplas configurações, refletindo características das sociedades contemporâneas.

Neste estudo, buscamos relacionar o saber teórico com as concepções construídas no cotidiano, perpassando as narrativas das alunas, no campo da memória, articuladas com a História da Educação, uma vez que o vínculo com a História não reside apenas nas divisões

\footnotetext{
${ }^{4} \mathrm{~A}$ ACADEPOL/SC atualmente funciona na Rua Tertuliano Brito Xavier, 209 - Bairro Canasvieiras, na cidade de Florianópolis, capital do Estado, sendo que no início das suas atividades esteve instalada no Bairro Estreito e, posteriormente, no Bairro Coqueiros, na mesma cidade.

${ }^{5}$ A Polícia Civil catarinense está organizada em quatro carreiras: Agente de Polícia, Delegado de Polícia, Escrivão de Polícia e Psicólogo Policial, cujas nomenclaturas dos cargos atende às orientações gramaticais da Língua Portuguesa que define o gênero masculino como sendo o coletivo. No entanto, faremos uso do gênero feminino para denominar esses cargos quando forem ocupados por mulheres (Delegada de Polícia, Escrivã de Polícia e Psicóloga Policial), a fim de assumir uma postura inclusiva, via linguagem, mesmo porque é assim também que essas policiais se intitulam.
} 
do tempo e datas dos eventos do passado, mas, segundo Lopes e Galvão (2001, p. 27), na compreensão do presente, intervindo "no futuro através do estudo do passado".

A condução da presente pesquisa, na perspectiva da Nova História Cultural, entende que homens e mulheres deixam de ser objetos e passam a ser sujeitos da História, procurando entender a sociedade e suas formas de sociabilidade. Essa concepção busca construir uma prática que se contrapõe aos procedimentos da História Tradicional/Positivista, a qual vê a história de forma linear e retilínea e se apresenta como "verdade absoluta", em que o "verdadeiro documento" é o oficial que, oficialmente, traduz uma história verdadeira (PESAVENTO, 2005).

Ao compreender que não existe uma história universal e total, mas várias histórias e recortes que compõem uma pluralidade, retomamos Rabelo (2007, p. 22) uma vez que "o passado está sendo construído e reconstruído a todo o momento, não é algo morto e sepultado, mas algo vivo e presente. Não é possível separar o passado do presente, pois formam um conjunto de experiências indissociáveis. Vivemos no nosso cotidiano temporalidades múltiplas, um tempo heterogêneo".

Assim, o percurso metodológico desta pesquisa se baseou em entrevistas e documentos oficiais encontrados na ACADEPOL/SC, nos quais foram coletadas informações relevantes para reconstrução da história da Escola de Polícia e das mulheres que frequentaram os cursos de formação. Com relação às entrevistas, foram selecionadas oito mulheres policiais, com base em três critérios: ter frequentado os Cursos de Formação da ACADEPOL/SC entre os anos de 1967 a 1977; estar na ativa, exercendo suas funções policiais e ter frequentado Cursos de Formação em anos diversos. Dessa forma, foram entrevistadas $^{6}$ : Joana (nome fictício a pedido da entrevistada que não autorizou a divulgação de seu nome); Sonia Maria Vieira; Neli Lucia de Medeiros; Lúcia Maria Périco (In memória, que se assinava Lúcia Maria Stefanovich); Odete Besen Formighieri; Maria Raquel da Silva; Darci Maria Waltrich e Maria de Fátima de Souza Ignácio.

Nesse processo, ao evocar as memórias das oito policiais que atenderam ao chamado da pesquisa, de acordo com Benjamin (1987), é preciso levar em consideração o meio onde se deu a vivência, o terreno a ser garimpado e o solo a ser desbravado. Nas palavras do autor:

\footnotetext{
${ }^{6}$ As entrevistas ocorreram nos meses de fevereiro e março de 2012.
} 
A memória não é um instrumento para exploração do passado; é antes, o meio. É o meio onde se deu a vivência, assim como o solo é o meio no qual as antigas cidades estão soterradas. Quem pretende se aproximar do próprio passado soterrado deve agir como um homem que escava (BENJAMIN, 1987, p. 239).

Como um solo soterrado, o passado é muito complexo e por mais que se remexa ou se escave, torna-se impossível recuperá-lo, pois ao tentar reconstruí-lo o visualizamos com as inquietações do presente. É preciso encontrar vestígios, amparados por uma metodologia rigorosa que permita reconstruir o passado.

A memória não é um fenômeno de interiorização individual, mas uma construção social e um fenômeno coletivo, sendo, muitas vezes, modelada pelos próprios grupos sociais. Para Bosi (1994), “a memória do indivíduo depende do seu relacionamento com a família, com a classe social, com a escola, com a igreja, com a profissão; enfim, com os grupos de convívio e os grupos de referência peculiares a esse indivíduo" (BOSI, 1994, p. 54).

Para trabalhar com as memórias das primeiras alunas dos cursos de formação da ACADEPOL/SC o recurso metodológico da História Oral temática foi utilizado, tendo em vista que o objetivo era analisar, através dos depoimentos, um determinado período histórico e as experiências vivenciadas nele.

\section{O TRABALHO DOCENTE NA MEMÓRIA DAS PRIMEIRAS MULHERES EM FORMAÇÃO NA ACADEPOL/SC}

$\mathrm{O}$ ingresso das mulheres na Polícia Civil e, consequentemente, na ACADEPOL/SC, não está dissociado do movimento de entrada das mulheres no mercado de trabalho. O depoimento de Joana, ilustra esse movimento:

Eu acredito que naquela época (1970) a mulher começou a se projetar na vida profissional, porque até então ela era muito presa às atividades domésticas e filhos. E de repente houve uma revolução em que a mulher começou a se projetar profissionalmente. [...] $\mathrm{O}$ fato de ser policial naquela época era diferente, nós fomos as primeiras a passar em concurso. O concurso não foi fácil, se não me engano tinha em torno de oitocentos candidatos ${ }^{7}$.

É nessa época também que se alavanca a possibilidade de maior inclusão das mulheres nas diversas profissões, incluindo a Polícia Civil. Segundo Pedro (2012), o processo acelerado de urbanização, intensificado a partir dos anos de 1970, fez das mulheres personagens visíveis em diversos espaços públicos, como universidades e em empregos formais.

\footnotetext{
${ }^{7}$ Joana. Entrevista citada.
} 
O ingresso ao mercado de trabalho, decorrente da transposição das barreiras entre o privado e o público pelas mulheres, traz consigo problemas. Um deles se expressa, geralmente, na ocupação de postos mais baixos na hierarquia funcional em relação aos ocupados pelos homens.

Para Brasil (2008), a inserção das mulheres em instituições policiais não está desvinculada do crescimento de seu ingresso no espaço público e no mundo do trabalho contemporâneo. "Os estudos de gênero revelam que a entrada das mulheres no mundo do trabalho globalizado tem crescido, expressando uma tendência de inserção em alguns ramos antes considerados como "guetos masculinos", como é o caso das instituições policiais" (BRASIL, 2008, p. 11).

Segundo Lúcia, “a opção pela carreira veio pela convivência durante meu curso de direito com policiais, alguns eram comissários, outros já pretendiam fazer concurso para Delegado" $"$. Narra ainda, que seus familiares ficaram preocupados com o seu ingresso. Segundo ela, era comum que o pai dissesse: “que profissão é essa que essa menina escolheu!”. Lúcia ainda diz que, até então, "não existia mulher nenhuma ocupando esse cargo, mesmo assim, minha família sempre me apoiou, mas sempre muito preocupada" ${ }^{9}$.

Nesse cenário, observou-se que mulheres decidiram sair do espaço doméstico e ingressaram no mercado de trabalho em busca de uma carreira profissional. Um dos enfrentamentos realizados por elas foi com as próprias famílias que, de alguma forma, ao tentar protegê-las, reforçavam a noção de que o sexo feminino é frágil.

Com relação ao espaço docente, o salário, três vezes maior, de que o valor pago à função de professora, foi o que motivou Darci a prestar concurso para Polícia Civil, conforme o explicitado no excerto de sua narrativa:

Eu não tinha amigos e nem familiar nesse meio, isso foi uma opção minha. Simplesmente queria ver a diferença do trabalho. O que me levou foi a curiosidade e também um pouco do vencimento, que na época que eu lecionava, dentro da minha área de escrivã de polícia, ganhava três vezes a mais ${ }^{10}$.

Além do salário mais elevado, outra questão que chama a atenção na narrativa de Darci é a curiosidade dela sobre a carreira policial. Ela queria saber a diferença entre ser professora e policial. Podemos inferir que ela não se moldou às representações impostas às mulheres pelo imaginário social da sua época. Ela decidiu ousar quando deixou o ambiente feminino do magistério para ingressar no ambiente masculino da polícia.

\footnotetext{
${ }^{8}$ Lúcia Maria Stefanovich. Delegada de Polícia. Entrevista citada.

${ }^{9}$ Lúcia Maria Stefanovich. Entrevista citada.

${ }^{10}$ Darci Maria Waltrich. Entrevista citada.
} 
Darci deixa claro em sua fala que tinha consciência de que para as mulheres saírem daquela condição do mundo privado em que viviam, deveriam estudar. Assim, ela disse aos familiares, logo cedo: "eu não quero mais saber de trabalhar na roça, eu quero é estudar" $" 11$.

Diversas foram as motivações que levaram as entrevistadas a ingressarem na carreira policial, desde a influência familiar, passando pela perspectiva de um trabalho novo e até a possibilidade de um salário maior.

Um aspecto que merece destaque é que quatro das entrevistadas (Joana, Odete, Raquel e Darci) mencionaram em suas narrativas sobre a profissão docente. Algumas tiveram experiências com trabalho em sala de aula e não gostaram, alegando descontentamento com a profissão, por não se adaptarem, por não se sentirem preparadas ou até porque pretendiam receber melhores salários, como se vê a seguir:

\begin{abstract}
A minha formação era para ser professora primária. Justamente naqueles anos que me formei, inventaram a prova de estágio, e eu não passava na prova de estágio, lecionei apenas dois anos como professora substituta e depois passei no concurso da polícia [...] também pelo salário, como professora substituta eu ganhava Cr\$100,00 e quando fui nomeada eu ganhava $\mathrm{Cr} \$ 770,00^{12}$.

Eu não sei o que me deu... deu uma loucura e eu disse: "eu vou" [fazer concurso para policial], também acho que não gostei do negócio de dar aulas, não gostei deser professora. Certo dia minha madrinha pediu para eu ficar um mês dando aulas em seu lugar, mas não gostei muito, porque era muito presa ${ }^{13}$.

$\mathrm{Na}$ época eu era professora primária. No final do ano cheguei da escola e vi uma notícia dizendo que tinha concurso para polícia civil, mas eu nem sabia prá quê servia. Passei no concurso e pedi exoneração da educação para a secretaria de segurança, mais por curiosidade, para ver como é que era o trabalho e também, pelo vencimento ${ }^{14}$.
\end{abstract}

Joana, era professora formada no Colégio Normal da cidade de Biguaçu/SC. Sobre o seu ingresso na Polícia, ela diz: "trabalhei na Farmácia Catarinense primeiro, depois fui ser professora, trabalhava com crianças, mas não era o que queria ainda. E quando saiu o concurso para a Polícia Civil eu me empolguei e fiz ${ }^{15}$ ".

Nesse período em que as entrevistadas ingressaram na polícia, a docência ainda era considerada uma das profissões mais recomendadas às mulheres, em função do processo de feminização do magistério. Porém, algumas das entrevistadas afirmaram que não queriam ser professoras, certamente porque almejavam alternativas de trabalho diferenciadas, num mercado que estava em expansão, pois era possível alçar voos em outras frentes de trabalho.

\footnotetext{
${ }^{11}$ Darci Maria Waltrich. Entrevista citada.

${ }^{12}$ Odete BesenFormighieri. Entrevista citada.

${ }^{13}$ Maria Raquel da Silva. Entrevista citada.

${ }^{14}$ Darci Maria Waltrich. Entrevista citada.

${ }^{15}$ Joana. Entrevista citada.
} 
Observamos que entre as mulheres que saíram do Magistério para ir para a polícia, um dos aspectos que as estimulou foi a questão salarial, talvez movidas pela necessidade de independência econômica. Isso implica refletir sobre a desvalorização salarial do Magistério desde aquela época. Ressalta-se, porém, que essa valorização mencionada pelas entrevistadas sobre o salário da Polícia Civil da época não perdurou, visto que, atualmente, é a questão salarial um dos grandes descontentamentos da categoria.

Para Louro (2011), no Brasil, é possível identificar algumas transformações sociais que, ao longo da segunda metade do século XIX, vão permitir não apenas a entrada das mulheres nas salas de aula, mas, pouco a pouco, o seu predomínio como docentes. A mulher, então, está associada à professora, não somente na sala de aula, mas sobretudo na sociedade; elas são compreendidas como mães dos alunos/as, comumente lhes agregando também as marcas religiosas, ligadas ao caráter de um ser dócil - que ama, que protege preceitos que estão, intimamente ligados à profissão docente (LOURO, 2011).

Mesmo a docência sendo recomendada para as mulheres, a Delegada Lúcia ${ }^{16}$ não desejava atuar na área, apesar de ter feito o Curso Normal. Assim, narra: "vim para Florianópolis, para o internato do Colégio Coração de Jesus. Fiz meu ginásio e, embora não quisesse ser professora, fiz o Curso Normal”.

A condição de Lúcia como normalista é fruto de um processo histórico, pois desde o século XIX, pouco a pouco os homens vão abandonando as salas de aula e as escolas normais vão formando mais e mais mulheres. Essa característica mantém-se por todo o século XX, estimulada, sobretudo, pelas intensas transformações econômicas, demográficas, sociais, culturais e políticas por que passa o país e que acabam por determinar uma grande participação feminina no mercado de trabalho em geral (VIANA, 2001/2).

A desistência do Magistério e o ingresso na profissão policial talvez tenha significado um grande desafio, uma vez que para se adequarem ao rigor do ofício, as mulheres suportaram uma longa e árdua aprendizagem, como forma de garantia de sobrevivência nesse mundo masculino, aliado ao desejo da estabilidade no mundo do trabalho com as transformações necessárias do próprio modelo de polícia.

O ingresso das mulheres na Polícia Civil é entendido, então, pela maioria das entrevistadas, como consequência da época, em que o contexto social desafiava as mulheres pela busca de outros espaços, até então masculinos. Isso, certamente, veio acompanhado por barreiras culturais, sociais e históricas. Passar pela ACADEPOL/SC significou vivenciar

\footnotetext{
${ }^{16}$ Lúcia Maria Stefanovich. Entrevista citada.
} 
situações novas para o mundo feminino. Estas mulheres escolheram a Polícia Civil como carreira e foi nela que construíram suas identidades profissionais. Formas de agir e pensar são alteradas dentro de uma instituição masculinizada, permitindo supor que as subjetividades e os comportamentos das mulheres foram sendo ressignificados pelo ambiente institucional.

Mesmo sendo um espaço masculino que apresenta dificuldades para o ingresso das mulheres, gerando dúvidas, tanto no momento da escolha da profissão, como na trajetória ao longo da carreira, observa-se, de modo geral, que as mulheres que ingressaram na polícia, permaneceram em suas funções, como é o caso das entrevistadas. Isso permite a constatação de que este espaço também é feminino e que as funções podem ser desempenhadas tanto por homens, quanto por mulheres.

\subsection{E na ACADEPOL quem lecionava?}

$\mathrm{Na}$ mesma ordem de uma escola regular, o Curso de Formação seguia com normas, práticas, disciplinas, técnicas de ensino, provas, etc., no entanto, diferente da escola regular, cabia aos homens, a maioria Delegados de Polícia, o ofício da docência ${ }^{17}$.

Entre os professores que lecionavam, as entrevistadas têm lembrança de uma única mulher, psicóloga de formação, que ministrava as disciplinas de Relações Humanas e Psicologia. Uma das alunas recorda que essa mulher era esposa de um dos professores e, talvez, somente por isso, estava inserida no quadro docente: "tinha uma professora de Psicologia, a doutora Leda. Era uma loira muito bonita e era casada com o Professor Edmundo" $" 18$.

Duas entrevistadas recordam que eram somente homens: "os professores eram delegados, Otacílio Schuller Sobrinho, Rodolfo, e outros que eu não lembro o nome ${ }^{19}$ ". Sobre esta questão Neli assim se manifesta: "não lembro de mulheres professoras na minha turma, só tinha professores" ${ }^{20}$. A presença de uma única professora nas lembranças das entrevistadas sugere a seguintes indagações: Por que somente uma mulher atuou como professora na ACADEPOL/SC, no período estudado? Por que esta única professora assume a disciplina de Relações Humanas e Psicologia? Importante considerar que nessa mesma época a escola regular é marcada pela feminização do magistério. Talvez uma das principais explicações

\footnotetext{
${ }^{17}$ Atualmente os professores/as da ACADEPOL/SC também fazem parte do quadro funcional da Polícia Civil e mediante Edital de Seleção são aprovados para atuar como docentes nos cursos lá promovidos, tendo que conciliar a função policial, no seu local de lotação, com as aulas na ACADEPOL/SC.

${ }^{18}$ Odete BesenFormighieri. Entrevista citada.

${ }^{19}$ Joana. Entrevista citada.

${ }^{20}$ Neli Lúcia de Medeiros. Entrevista citada.
} 
esteja no fato de a Academia ser um ambiente de domínio masculino, reflexo da própria composição da categoria.

Esse arranjo relembra o início do Magistério, quando os homens eram a maioria. À medida em que a sociedade vai se industrializando, o perfil da profissão vai sendo alterado. Os homens vão para fábricas e as mulheres vão para sala de aula. O Magistério se tornará, nesse contexto, uma atividade permitida e indicada para as mulheres, passando por um processo de ressignificação (LOURO, 2011).

Fica evidente que o conteúdo ensinado na perspectiva masculina denota, de forma profunda, uma cultura escolar com as marcas do gênero masculino. Assim, as práticas escolares apresentam traços cristalizados que expressam padrões tradicionais e polarizados acerca das relações dos homens e mulheres. De todo modo, é possível notar, concomitantemente, que as fronteiras de gênero se cruzaram no cotidiano da ACADEPOL/SC.

O processo de formação do/a policial se constrói nas relações dentro e também fora da escola, entre si e os/as colegas e no próprio espaço de trabalho. É também na atuação profissional que são formadas e reproduzidas as desigualdades de gênero que se naturalizaram e refletiram na trajetória dessas policiais.

\section{CONSIDERAÇÕES FINAIS}

Entender o espaço docente na formação policial oportunizou a percepção da importância de problematizar questões de gênero, pois as mulheres enquanto alunas e professoras ocupam espaços e, mesmo sendo espaços masculinos, as fronteiras do gênero se cruzaram no cotidiano escolar.

A profissão policial é uma categoria social construída mediante conflitos e é atravessada por relações de poder, como o que ocorre em diversas outras profissões da sociedade contemporânea, inclusive na docência. $O$ trabalho se orienta por saberes apreendidos e práticas vivenciadas na formação profissional, bem como pelas relações cotidianas na sua rotina, indissociáveis à trajetória dos sujeitos.

As mulheres entrevistadas ingressaram na polícia na década de 1970, um momento histórico marcado pela ditadura militar no país, pela entrada intensa das mulheres no mercado de trabalho, bem como pela efervescência das lutas feministas. Eram mulheres de realidades singulares, pois são oriundas de famílias de classes sociais diferentes, frequentaram 
cursos de formação diferentes, tinham motivações distintas para o ingresso na instituição, o que resultou na construção de histórias e trajetórias profissionais diferentes. Todas essas interlocuções contribuíram para a construção, não de uma única identidade profissional, mas distintas identidades profissionais.

Há de se mencionar que a escolha pela polícia parece estar vinculada à conjuntura da época, em que a mulher busca maior escolarização e, ao mesmo tempo, o mercado de trabalho surge como uma necessidade. Outra questão a ser observada é que muitas delas já seguiam ou "deveriam" seguir para a docência, profissão mais apropriada para as mulheres à época, mas burlaram a ordem "natural" imposta pela sociedade e escolheram uma profissão com perspectivas salariais maiores.

O fato de as entrevistadas lembrarem de uma única professora nos seus processos de formação na ACADEPOL/SC, leva-nos a supor que as marcas do masculino estiveram muito presentes na formação dessas policiais e, certamente, reverberaram em suas práticas profissionais.

Nesse contexto, a entrada das mulheres nesse espaço profissional de domínio historicamente masculino, necessariamente exigiu a construção de uma nova cultura de ensino, no entanto, as marcas do gênero masculino continuavam presentes fortalecendo o monopólio dos homens e contribuindo para a invisibilidade das mulheres.

\section{REFERÊNCIAS}

BENJAMIN, Walter. Obras escolhidas: rua de mão única. 2. ed. São Paulo: Brasiliense, 1987.

BOSI, Ecléa. Memória e Sociedade: lembrança de velhos. 3. ed. São Paulo: Companhia das letras, 1994.

BRASIL, Glauciria Mota (org.). A Face feminina da Polícia Civil: gênero, hierarquia e poder. Fortaleza: Ed. UECE, 2008.

BRANDÃO, Carlos Rodrigues. O que é Educação. São Paulo: Brasiliense, 2007.

LOURO, Guacira Lopes. Gênero, sexualidade e educação: uma perspectiva pósestruturalista. 12. ed. Petrópolis: Vozes, 2011.

LOPES, Eliane Marta T.; GALVÃO, Ana Maria de O. História da Educação. Rio de Janeiro: DP\&A, 2001. 
PEDRO, Joana Maria (Org.). Nova História das mulheres no Brasil. São Paulo: Contexto, 2012. p. 238-259.

PESAVENTO, Sandra Jatahy. História \& História Cultural. 2. ed., 1 reimp. Belo Horizonte: Autêntica, 2005.

RABELO, Giani. Entre o hábito e o carvão: pedagogias missionárias no Sul de Santa Catarina na segunda metade do século XX. 2007. 414 f. Tese (Doutorado em Educação)Faculdade de Educação, Universidade Federal do Rio Grande do Sul, Porto Alegre, 2007.

VIANA, Cláudia Pereira. O sexo e o gênero da docência. Cadernos Pagu, 17/18, p. 81-103, 2001/02. Disponível em: 〈http://www.scielo.br/pdf/cpa/n17-18/n17a03.pdf> acesso em: 1 mar. 2013.

\section{FONTES ORAIS}

Darci Maria Waltrich.Nasceu em 27/07/1949. Entrevista concedida à Maria Aparecida Casagrande em 04/05/2012, em Criciúma/SC.

Joana. Nasceu em 1947. Entrevista concedida à Maria Aparecida Casagrande em 01/03/2012, em São José/SC.

Lucia Maria Perico (in memória). Nasceu em 08/12/1947. Entrevista concedida à Maria Aparecida Casagrande em 02/03/2012, em Florianópolis/SC. A Delegada de Polícia assina pelo nome de Lúcia Maria Stefanovich.

Maria de Fátima de Souza Ignácio. Nasceu em 04/03/1954. Entrevista concedida à Maria Aparecida Casagrande em 14/03/2012, em Navegantes/SC.

Maria Raquel da Silva. Nasceu em 26/01/1949. Entrevista realizada em 13/03/2012 no setor de Recursos Humanos - Florianópolis/SC.

Neli Lúcia de Medeiros. Nasceu em 26/06/1950. Entrevista concedida à Maria Aparecida Casagrande, em 29/02/2012, em Palhoça/SC.

Odete Besen Formighieri. Nasceu em 12/11/1950. Entrevista concedida à Maria Aparecida Casagrande em 29/02/2012, em Florianópolis/SC.

Sonia Maria Vieira. Nasceu em 22/04/1950. Entrevista concedida à Maria Aparecida Casagrande em 01/03/2012, em Florianópolis/SC. 